\section{Factors affecting treatment preferences of chronic pain patients in primary care and current treatment options in chronic pain}

\section{Birinci basamakta kronik ağrılı hastaların tedavi tercihlerini etkileyen faktörler ve kronik ağrida güncel tedavi seçenekleri}

\author{
Hayriye Alp ${ }^{1}$
}

\begin{abstract}
Research problem/aim: In a multicenter study of the World Health Organization, 22\% of patients who applied to primary health care centers reported that their pain continued for 6 months. Multidisciplinary approach and empathy are important for patients with chronic pain. $20 \%$ of first-line outpatient referrals consist of chronic painful cases. When the analgesics are used correctly in the treatment of pain, sufficient pain control can be achieved in $85 \%$. Non-steroidal and steroid analgesics may present with high doses of gastrointestinal side effects.

Method: The sociodemographic characteristics of the participants were recorded on the forms prepared by the researchers.
\end{abstract}

Finding: The mean age of the patients was $58.62 \pm 10.72$.Pain was found to affect sleep. $(* \mathrm{p}<0.05)$

Conclusion: The patient sector, which is far from rational drug use, can cause great harm to the country's economy. With the extensive studies to be carried out, the treatment method of the patients and the reasons why they prefer. It will be helpful for the chronic pain patients to get the right information from their doctors about the treatment options. For this reason,
Özet

Araştırma problem/amaç: Dünya Sağlık Örgütünün çok merkezli yapılan bir araştırmasında birinci basamak sağlık merkezlerine başvuran hastaların \%22'sinde ağrılarının 6 aydır devam ettiği belirtilmektedir. Kronik ağrısı olan hastalara multidispliner yaklaşım ve empati önemlidir. Birinci basamak poliklinik başvurularının \%20'si kronik ağrılı olgulardan oluşmaktadır. Ağr1 tedavisinde analjezikler doğru kullanıldığında \%85'inde yeterli ağr1 kontrolü sağlanabilmektedir. Nonsteroid ve steroid analjezikler yüksek dozlarda gastrointestinal yan etkilerle karşımıza ç1kabilmektedir.

Metot: Katilımciların sosyodemografik özellikleri araştırmacılar tarafindan önceden hazırlanan formlara kaydedildi.

Bulgular: Çalışmaya katılan hastaların ortalama yaşları $58.62 \pm 10.72$ olarak tespit edildi. Ağrının uykuyu etkilediği bulunmuştur. $(* \mathrm{p}<0,05)$

Sonuçlar: Akılcı ilaç kullanımından uzak hasta kesimi ülke ekonomisine büyük zararlar verebilmektedir. Yapılacak geniş kapsamlı çalışmalar ile hastaların hangi tedavi yöntemini, neden tercih ettikleri konusu daha açığa kavuşacaktır. Kronik ağrı hastalarının tedavi seçenekleri hakkında doktorlarından doğru

Doktor Öğretim Üyesi, Necmettin Erbakan Üniversitesi, Meram Tip Fakültesi, Getata Merkezi, hayriyebalp@yahoo.com 
Alp, H., (2019). Birinci basamakta kronik ağrılı hastaların tedavi tercihlerini etkileyen faktörler ve kronik ağrıda güncel tedavi seçenekleri. Journal of Human Sciences, 16(3), 781-790. doi:10.14687/jhs.v16i3.5556

family physicians should be equipped with upto-date information about all methods used in chronic pain treatment.

Keywords: Primary care; chronic pain; treatment; factor; current.

Extended English summary is at the end of this document) bilgi alması kendisine en uygun yöntemi seçmesi konusunda yol gösterici olacaktır. Bunun için de aile hekimlerinin kronik ağrı sağaltımında kullanılan tüm yöntemler hakkında güncel bilgilerle donanımlı olması gerekmektedir.

Anahtar Kelimeler: Birinci basamak; kronik ağrn; tedavi; faktör; güncel.

\section{Giriş}

Evrensel olarak ağrı tanımı, 1979 yılında Uluslararası Ağrı Teşkilatı tarafindan 'doku hasarı veya potansiyel doku hasarı ile birlikte olan ya da bu hasar süresince deneyimlenen hoş olmayan deneyim ‘ şeklinde yapılmaktadır. Ağnı tüm dünyada giderek artan bir sağlık problemi olmaya devam etmektedir. Üç aydan uzun süren ağrılar kronik, üç aydan daha kısa süren ağrılar akut ağrı olarak tanımlanır.

Kronik ağrı kişinin fonksiyonunu ve yaşam kalitesini olumsuz etkileyen bir ağrıdır. Akut ağrının içerdiği koruyucu fizyolojik mekanizmaları içermez, tanımlanması oldukça güçtür. Nosiseptif, nöropatik veya miks tiplerde karşımıza çıabilir. Birinci basamak sağlık merkezlerine başvuran hastaların yaklaşık \%10-20'si kronik ağrıdan yakınmaktadır(1).Dünya Sağlık Örgütünün (DSÖ) çok merkezli yapılan bir araştırmasında birinci basamak sağlık merkezlerine başvuran hastaların \%22'sinin ağrılarının 6 aydır devam ettiği belirtilmektedir (2). Gelişmiş ülkelerde bu oran \%15‘den \%55.2’ye kadar yükselmektedir. Avrupa da her beş kişiden biri kronik ağrıdan yakınmaktadır $(3,4)$.

\section{Amaç}

Çalışmamızda hem ülkemiz hem de tüm dünyada bu kadar yüksek sıllı̆ga sahip olan, kronik ağrılı hastaların demografik özellikleri ile tedavi tercihlerini araştırmayı planladık. Kronik ağrısı olan hastanın ağrısının şiddeti, ortaya çıkışı, yayılımı, eşlik eden faktörleri, ağrı öncesi ve sonrasında yaşadığı psikolojik durumu, ailevi özellikleri, altta yatan kronik hastalık varlığı, alışkanlıkları sorgulandı. Şimdiye kadar aldıkları tedavileri ve bu tedavilerden beklentilerini, ayrıca ağrı şiddetinde \% 30 oranında iyileşme olup olmadığını sorgulandı. Amacımız birinci basamak sağlık merkezlerine başvuran kronik ağrılı hastaların tedavi tercihlerini demografik özellikleriyle ortaya koymak, ağrı şiddetlerine etki eden faktörleri tespit etmektir.

\section{Metod}

Katılımcıların sosyodemografik özellikleri araştırmacılar tarafından önceden hazırlanan formlara kaydedildi. Anket hastalara aile hekimi tarafindan yüz yüze uygulandi. Anket soruları arasında hastaların demografik özellikleri yanısıra ağrının özellikleri de yer aldı. Ağrının başlangıcı, yayılım, süresi, şiddeti, zonklayıcı özelliği, başlatan durumlar sorgulandı. Hastanın daha önce kronik ağr1 nedeniyle aldığ1 tedavileri soruldu. Hastaların daha önceden geçirilmiş olan travma ve hastalık varlığı not edildi. Hastaların kronik ağrısının uykuyla ilişkisi araştırıldı. Kronik ağrılı hastaların yaşadığı ortam, aile öyküsü, mesleği, postür alışkanlıkları, hayata psikolojik bakış açısı hakkında bilgi edinildi. Kronik ağrı tedavisinin öncesi ve sonrası hastaların ruhsal durumu incelendi. Hastaların ağrısına yönelik yapılan tedavi uygulamalarının sonucundan nasıl bir beklenti içinde olduğu soruldu.

\section{Çalışmanın yeri ve zamanı}

Çalışmanın evrenini Konya Aile Sağlı̆̆ı Merkezi’nde görev yapan aile hekimine kayıtlı hastalar oluşturmaktadır; çalışma, 01.10.2015-30.12.2015 tarihleri arasında üç ay süresince yapılmıştır. 
Alp, H., (2019). Birinci basamakta kronik ağrılı hastaların tedavi tercihlerini etkileyen faktörler ve kronik ağrıda güncel tedavi seçenekleri. Journal of Human Sciences, 16(3), 781-790. doi:10.14687/jhs.v16i3.5556

\section{Popülasyon ve örnek seçimi}

Aile Sağllğı Merkezi'nde görev yapan aile hekimine kayıtlı hastalar ve kronik ağrisı olanlar

\section{Çalı̧̧manın tipi}

Tanımlayıcı tipte olan bu çalışma, 01.10.2015-30.12.2015 tarihleri arasında yapılmıştır.

\section{Değişkenler}

Sosyodemografik özellikler; cinsiyet, yaş, ağrı düzeyi(VAS), kronik hastalıklar, postür, psikolojik durum, uykudur.

\section{Veri Toplanmasi}

\section{Veri toplama metodu}

Vizüel Ağrı Skoru (VAS); Ağrı skoru olarak Price ve arkadaşları tarafindan geliştirilmiştir (5).Geçerlilik ve güvenirliliği yapılmış bir ölçektir. Yaklaşık $10 \mathrm{~cm}$ boyutundadır; vertikal veya horizontal düzlemde iki uç kısmında numaralar en küçükten en büyüğe doğru sıralanmaktadır(sıfır yani en düşük numara=ağrının şiddetinin neredeyse hiç yok olduğu, on yani en yüksek Numara ağr1 şiddetinin en yüksek derecede olduğunu göstermektedir.) Ağrisı olan kişinin düzlem üzerinde ağrısının nereye tekabül ettiğini göstermesi istenir. Gösterilen yerin sıfır noktasına uzaklı̆̆ının kaç santimetre olduğu ağrısının derecesini kantitatif olarak belirleyen skordur. Araştırmacı tarafindan hastalara VAS'ın ne olduğu iyice izah edildikten sonra bu ölçeği işaretlemeleri istendi.

\section{Veri toplama araçları}

Hastalara yüz yüze anket uygulandı.Yapılan çalışmanın verileri bilgisayarda Statistical Package for Social Sciences(SPSS) for Windows 20 programına aktarıldı. Analiz sonuçları ortalama ve standart sapmaları ile frekans ve yüzdeleri hesaplandı.

\section{Veri toplama zamanı}

Araştırma 01.10.2015-30.12.2015 arasında yapıldı.

\section{Çalışmanın kısıtlılıkları}

Bu çalışma merkez sağllk ocağında tek bir aile hekimine başvuran kısıtlı sayıdaki hastalar üzerinde yapılmıştır. Örneklem sayısının daha fazla olduğu, çok merkezli geniş çapta çalışmalara ihtiyaç duyulmaktadır. . Yapılacak geniş kapsamlı çalışmalar hastaların hangi tedavi yöntemini, neden tercih ettikleri konusunda daha açılayıcı olacaktır.

\section{Çalışmanın Genelleştirilebilirliği}

Çalışmalarda anamnez alırken, hastayı hastanın ifadelerine karışmadan, etkili iletişim yöntemi kurarak dinlemek en doğru tutum olmaktadır. Ağrının başlangıcı, bitişi, süresi, şiddeti, zonklayıcı özelliği, ağrıyı başlatan durumlar, ağrının yayılımı, ağrının uykuyla olan ilişkisi, hastanın önceki tedavileri ve bu tedavilerin ağrı üzerine etkisi sorgulanmalıdır. Hastanın ağrılı dönemleri, geçirilmiş travmaları, hastalıkları, mesleği, yaşadığı ortam, alışkanlıkları, hayata bakışı, postür alışkanlıkları, aile öyküsü, ağr1 öncesi ve sonrası ruhsal durumu, ağr1 tedavisine karşı beklentisi sorgulanmalıdır. Hastanın ağrısını etkileyen faktörler; yaş, cinsiyet, eğitim durumu, yaşadığı ortam, maddi durum olabilmektedir. Falla ve ark. yaptuğ bir çalısmada $(n=205)$, kronik ağr1lı hastaların ağr1 boyutunun hastanın cinsiyetinden ve finansal durumundan etkilendiği tespit edilmiştir(21).

Kronik ağrn, hastaların günlük yaşam aktivitelerini kısıtlayabilmektedir. Ağrn nedeniyle hastalar psikolojik olarak kötü hissetmekte, bozulan psikoloji ile kişinin ağrı algisını etkileyerek bir kısır döngüye girmektedir. Hastanın kişilik yapısı ve emosyonel durumu, ağrıyı algılamasında ve ağriyı dile getirmesinde önemli bir faktördür. Psikolojik olarak iyi durumda olan hasta ağnn eşiği yüksek ise ağr1 yakınması daha az olmakta, karamsar bir kişiliğe sahipse ağrı eşiği daha düşük olmaktadır. Depresyonlu kişiler ağnı düzeylerini abartılı şekilde gösterebilmektedir(22).Kişinin hayatı boyunca 
Alp, H., (2019). Birinci basamakta kronik ağrılı hastaların tedavi tercihlerini etkileyen faktörler ve kronik ağrıda güncel tedavi seçenekleri. Journal of Human Sciences, 16(3), 781-790. doi:10.14687/jhs.v16i3.5556

yaşadığ1 kazalar, hastalıklar, sosyokültürel yapısı, hissettiği ağrıyı ifade etmesini etkileyebilir. Yapılan bir çalışmada düşük sosyoekonomik düzeyin somatizasyonla ilişkili olduğu ortaya konmuştur(24).

\section{Araştırma Etiği}

Çalışma için Necmettin Erbakan Üniversitesi Meram Tip Fakültesi Etik Kurul izni alındı.(2016/421) Ayrıca ilgili Aile Sağlığı Merkezi Sorumlu Hekimi ve ilgili Toplum Sağlığı Merkezi Sorumlu Hekimi'nden izin alınarak yapılmıştır.

\section{Verilerin Değerlendirilmesi}

Yapılan çalışmanın verileri bilgisayarda SPSS for Windows 20 programına aktarıldı. Analiz sonuçları ortalama ve standart sapmaları ile frekans ve yüzdeleri hesaplandı

\section{Sonuçlar}

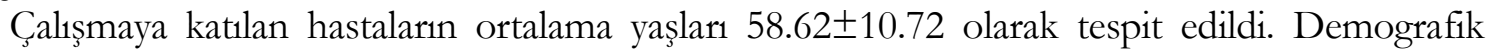
verilere göre hastaların \%80'ini çalışmayan kadınlar oluşturmuştur. Ağrının başladığı yer sorgulandığında hastaların \%34'ü bel bölgesinden \%22'si kalça-diz bölgelerinden,\%18’i bel-boyun bölgesini, \%10‘u omuz bölgesini başlangıç bölgesi olarak ifade etti. Bel ağnısının prevalansının yüksekliği literatürle uyumlu bulunmaktadır. Hastaların ağrılarının bitiş noktası sorgulandığında \%36's1 ayak, \%18’i omuz-sırt, \%12'si tüm vücut ve \%12'si baş olarak ifade etti. Kronik ağrının süresi sorulduğunda, hastaların \%78’i sürekli olarak ağrısının olduğunu belirtirken, \%10’u yürümekle ağrının olduğunu ifade etti. Kronik ağrının şiddeti sorgulandığında hastaların \%42'sinde VAS 3 iken \%28'inde VAS 5 şiddetinde idi. Ağnı şiddeti ile var olan hastalıklar arasında bir ilişki saptanamamıştır. Hastaların \%68'inde ağrnya zonklama eşlik etmiştir. Hastalara ağrıyı başlatan durumlar sorgulandı; \%34"ünde ayakta durmak, \%28'inde ise stress ve yorgunluk ağrıyı başlatmaktadır. Ağrıyı başlatan durumlar (ayakta durmak, stres, yorgunluk, soğuk gibi) ile yaş arasında bir ilişki bulunamamıştır. Ağrının vücuttaki yayılım bölgelerini \%28 ile ayak bölgesi, \%14 ile tüm vücut oluşturmuştur. Hastaların \%35’i ağrının uyku ile ilişkisi olmadığını belirtmiştir. Ağrı şiddetinin, yani VAS değerinin 4 ve üzerinde olduğu 23 hastada ağrının uykuyu etkilediği bulunmuştur.(* $\mathrm{p}<0,05)$ (Tablo.1).

\begin{tabular}{|c|c|c|c|c|}
\hline & \multicolumn{2}{|c|}{ Uyku ile İlişkisi } & \multirow{3}{*}{$\chi^{2}$} & \multirow{3}{*}{$\mathrm{p}$} \\
\hline & Evet & Hayır & & \\
\hline VAS & $\mathrm{n}(\%)$ & $\mathrm{n}(\%)$ & & \\
\hline 3 ve $\downarrow$ & $1(4)$ & $24(92)$ & \multirow{2}{*}{38,782} & \multirow{2}{*}{$0,001^{*}$} \\
\hline 4 ve $\uparrow$ & $23(96)$ & $2(8)$ & & \\
\hline Toplam & $24(100)$ & $26(100)$ & & \\
\hline$* \mathrm{p}<0,05$ & & & & \\
\hline
\end{tabular}

Yaş ile uyku arasında bir bağlantı tespit edilememiştir. Hastaların önceki tedavileri sorgulandığında; hastaların \%35'i non-steroid analjezik kullandığını ifade etmiştir. Hastaların \%76'sı ağr1l dönemlerini tüm gün boyunca hissettmiş, \%16's1 ise yürümekle ağr1 hissettiğini söylemiştir. Ağrı ile travma ilişkisi sorduğumuzda; hastaların \%86'sı travma öyküsünün olmadığını belirtmiştir. Kronik ağrılı hastaların \%96'sında kronik bir hastalık bulunmaktadır. Kronik ağrı hastalarının \%56'sı yaşadığı ortamı kötü olarak nitelendirmektedir. Hastalar alışkanlıkları açısından sorgulanmış; hastaların \%86's1 herhangi bir alışkanlığının olmadığını belirtmiştir. Hastaların \%56’sı ağrılı dönemlerinden sonra kendilerini huzursuz, gergin hissettikleri için psikolojilerinin etkilendiğini belirtmişlerdir. Hastaların kronik ağrılarının gün içerisindeki postürleri ile ilgisi sorgulandığında \%78’inde bir ilişki kurulamamıştır. Ağrı şiddeti ile postür (oturma, eğilme gibi) ve hastalıkları arasında bir ilişki bulunmamaktadır (Tablo.2). 
Alp, H., (2019). Birinci basamakta kronik ağrılı hastaların tedavi tercihlerini etkileyen faktörler ve kronik ağrıda güncel tedavi seçenekleri. Journal of Human Sciences, 16(3), 781-790. doi:10.14687/jhs.v16i3.5556

\begin{tabular}{|c|c|c|c|c|}
\hline & \multicolumn{2}{|c|}{$\begin{array}{l}\text { Ağriy1 Başlatan ya da } \\
\text { Arttran Postür (Eğilme) }\end{array}$} & & \\
\hline & Evet & Hayır & \multirow{2}{*}{$\chi^{2}$} & \multirow[b]{2}{*}{$\mathrm{p}$} \\
\hline VAS & $\mathrm{n}(\%)$ & $\mathrm{n}(\%)$ & & \\
\hline 3 ve $\downarrow$ & $6(54)$ & $19(48)$ & \multirow{2}{*}{0,117} & \multirow{2}{*}{0,500} \\
\hline 4 ve $\uparrow$ & $5(45)$ & $20(52)$ & & \\
\hline Toplam & $11(100)$ & $39(100)$ & & \\
\hline
\end{tabular}

Hastaların \%52'sinde kronik ağrı aile öyküsü mevcuttur. Ağr1 şiddeti ile aile öyküsü arasında bir ilişki bulunmamıstır(Tablo.3).

\begin{tabular}{|c|c|c|c|c|}
\hline & \multicolumn{2}{|c|}{ Aile Öyküsü } & & \\
\hline & Var & Yok & \multirow{2}{*}{$\chi^{2}$} & \multirow[b]{2}{*}{$\mathrm{p}$} \\
\hline VAS & $\mathrm{n}(\%)$ & $\mathrm{n}(\%)$ & & \\
\hline 3 ve $\downarrow$ & $10(48)$ & $15(52)$ & \multirow{2}{*}{0,082} & \multirow{2}{*}{0,500} \\
\hline 4 ve $\uparrow$ & $11(52)$ & $14(48)$ & & \\
\hline Toplam & $24(100)$ & $26(100)$ & & \\
\hline
\end{tabular}

Hastaların \%78’i kronik ağrılarındaki tedavisi sonrasında iyileşmenin, \%30 oranının altında kaldığını belirtmiştir. Hastaların hayata bakış açıları sorgulanmış; \%93’ünde kötümser psikolojik durum tespit edilmiştir.

\section{Tartışma}

Kronik ağrılı hastalar, birçok yönde sorgulanması gereken hasta grubunu oluşturmaktadır. Birinci basamak hekimleri bu tür hastalarla çok sık karşılaşmaktadır. Aile hekimleri insanı bir bütün olarak değerlendirmektedir. Kronik ağrılı hastalar sıklıkla sağlık kuruluşlarını gezmekte ancak eninde sonunda kendi aile hekimine başvurmaktadır. (12) Çoklu tedavi seçenekleriyle karşılaşan hastaların sorgulanabileceği en iyi ortamlar bu Aile Sağlığı Merkezleri olmaktadır. Aile hekimliği sistemine geçişle birlikte bu hasta gruplarına daha fazla zaman ayırabilen hekimler bu tür sorunları yönetebilmektedir. Ağrılı olgularda ağrının kendisi değil, ağr1l kişinin sağaltımı önemli olmaktadır. Kronik ağnı biyopsiko-sosyal bir durumdur. Kronik ağrının en iyi değerlendirilebileceği ve yönetilebileceği yer, günlük bakılan hasta sayısı açısından bakıldığında, kişi başına ayrılan zamanın daha uzun tutulduğu birinci basamak olan aile hekimlikleridir.

Hastaların tüm polikliniklere başvuru nedenleri incelendiğinde, üst solunum yolu enfeksiyonlarından sonra en sık başvuru nedeni ağnıdır. Literatür çalısmalarına bakıldığında ağn süresine göre, akut ve kronik olarak 2 sınıfa ayrılmaktadır. Kronik ağrıların en çok bel bölgesinden kaynaklandığı gösterilmektedir. Araştırma verilerine dayanarak toplumdaki kronik ağr1 s1klığ1 \%2-54 civarında bulunmaktadır. Yapılan çalışmalarda hastaların belirttiği ağrı düzeyinin, yaş ile doğru orantılı olarak arttı̆̆ı, tespit edilmiştir. Hastaların eğitim düzeyleri arttıkça ağıı düzeylerinde azalma olmaktadır. Cinsiyet olarak bakıldığında bayan cinsiyete sahip olan hastaların erkek cinsiyete göre daha çok ağnt tecrübe ettikleri tespit edilmektedir(6, 7, 8, 9, 10, 11, 12). Amerika Birleşik Devletlerinde her üç kişiden biri kronik ağrıdan yakınmaktadır(9). Ülkemizde prevalans konusunda çok az çalışma mevcuttur; Erdine ve ark. yaptığı çalışmada ağıı prevalansı \%63.7 tespit edilmektedir(6).

Kronik ağrılı olaylarda multidisipliner yaklaşım ve empati önemli olmaktadır. Birinci basamak poliklinik başvurularının \%20'si kronik ağrılı olgulardan oluşmaktadır. Ağrı tedavisinde analjezikler doğru kullanıldığında hastaların \%85'inde yeterli ağnı kontrolü sağlanabilmektedir. Farmakolojik olarak steroid ve non-steroid preparatlar öne çıkmaktadır. Kullanılan non-steroid ve steroid analjezikler uzun süre kullanımında yüksek dozlarda gastrointestinal yan etkilerle karşımıza çıkabilmektedir. Akılcı ilaç kullanımından uzak olan hasta kesimi ülke ekonomisine büyük zaralar verebilmektedir. Saragiotto ve ark.yaptı̆̆ bir meta analizde,1825 katılımcı üzerinde yapılan araştırma; akut bel ağrnlı hastalarda günde 4g. parasetamol kullanımının yaşam ve uyku kalitesi üzerine etkisinin 
Alp, H., (2019). Birinci basamakta kronik ağrılı hastaların tedavi tercihlerini etkileyen faktörler ve kronik ağrıda güncel tedavi seçenekleri. Journal of Human Sciences, 16(3), 781-790. doi:10.14687/jhs.v16i3.5556

plasebodan farklı olmadığını göstermektedir (13). DSÖ’nün kronik ağıı tedavisinde önerdiği basamak tedavisi göz önüne alınmalıdır. Birinci basamakta non opioid -zayıf opioid, ikinci basamakta orta etkili opioid, üçüncü basamakta ise güçlü opioid ilaçlar tedavide kullanılmalıdır. Analjezik ve antiinflamatuar ilaçlar kanser gibi ciddi vakalarda opioidler ile kombine şekilde kullanılabilmektedir(14). Opioid ilaçların kullanımında; ülkemizdeki opioid ilaç sayısının az olması, poliklinikte yazılabilmeleri için yeşil ve kırmızı reçete varlı̆̆1 gerektirmesi, opioid ilaç kullanımının olası yan etkileriyle hastaların baş etmede güçlük yaşaması, reçetelerin saklanması sırasında hem hasta hem de doktor açısından da mediko-legal sorunlar yaratmaktadır.

\section{Kronik Ağnda Güncel Yaklaşımlar}

Her hasta hayatının bir döneminde mutlaka kas-iskelet ağrısı yaşamaktadır. Toplumun yaklaşık \%80' i bel-boyun ağrısı şikâyeti ile yaşamaktadır. Ayakta iş yapan işçilerde zamanla alt bel ağrıları, masa başı iş yapanlarda ise boyun-omuz ağrıları sıklıkla karşılaşılmaktadır. Çalışanların çoğu doğru postür özelliklerini ya hiç bilmemekte, ya umursamamakta ya da koşullar gereği uygulayamamaktadır. Oysa postür bugün günlük hayatımızda çok önemli yer tutmaktadır. Ergonomik çalışma masaları, bilgisayarlar postüre ve vücut frame'ne olumlu etkiler sağlamaktadır. Frame vücudumuzun biyomekanik eksenini oluşturmaktadır. Geçirilmiş ameliyatlar, ergonomik olmayan çalışma koşulları vücudun frame' ini bozmaktadır. Frame’i bozulan vücut bunu dengede tutabilmek için yeni postürler geliştirmektedir. Oluşan postür dengesizlikleri kasların tonusunu, kas boylarını etkilemekte vücut ağıllı̆̆ eşit olarak dağılamamaktadır. Kasların etrafını saran fasyalar bu eşit dağılmayan yükün etkisiyle gerilmektedir. İç organlara yansiyabilen postür bozuklukları enfeksiyonlara zemin hazırlayabilmektedir. Örneğin öne eğimle yürüyen bir kadın hastada sürekli mesanesinde residü idrar birikimine bağlı olarak, tekrarlayan idrar yolu enfeksiyonları olabilmektedir. Postür bozukluklarında eklem instabiliteleri de önemli rol oynamaktadır. Postür bozuklukları ile postüroloji ilgilenmektedir. Tedavide hasta tek ayak üzerinde dengede durması sağlanarak instabilite olan taraf tesbit edilmekte ve instabilitenin olduğu ayak kavsine verilen $2 \mathrm{~mm}$ ' lik bir tabanlık postüre bağlı sorunlar basitçe giderilmektedir. Ayrıca doğru postürü oluşturmada tamamlayıcı tıp uygulamalarından proloterapiden de yararlanılmaktadır.(15)

Proloterapi özellikle ligaman instabilitelerinde tedavi amaçlı olarak kullanılmaktadır. Ligaman instabilite tanısı ortopedi, fizik tedavi uzmanları proloterapi eğitimi alan hekimler tarafindan konabilmektedir.Ligaman instabiletesi sporcular yanısıra bir çok dejeneratif eklem hastalıklarında da görülmektedir. Farklı nedenlerle opere olmuş hastalarda da gelişebilen ligaman instabiliteleri hastada yansıyan ağrılar ortaya çıkarabilmektedir. Proloterapi gibi tamamlayıcı tıp uygulamaları ile bu tür vakalarda opere olmak istemeyen ileri yaş dejeneratif kemik hastallğı olan hastalara yeni seçenekler sunmaktadır. Uygun hastalarda doğru bir anamnez ve fizik muayene ile instabiliteler tespit edilebilir uygun teknikle eklem çevresine enjeksiyonlar yapılarak ligamanlar kuvvetlendirilebilir. Böylece daha büyük cerrahi girişimler ötelenebilmektedir. Dejeneratif eklem hastalıklarının neden olduğu kronik ağrilı durumlarda proloterapi oldukça önemli yer teşkil etmektedir. Eklem çevresine \%15' lik dextroz içeren enjeksiyonlar yapılır, enjeksiyon yapılırken iğne mutlaka kemiğe temas ettirilir. Böylece steril bir enflamasyon oluşturarak, ligamanların kan dolaşımı artırılması amaçlanmaktadır. Enjeksiyon bölgesinde osteoblast ve fibroblastlar aktive edilerek rejenerasyon süreci başlatılmaktadır. Enjeksiyon günü lokal ısıtıcıların kullanılması önerilmektedir. 3 hafta aralıklarla yapılan enjeksiyon tekrarlanır. Tedavi boyunca $\mathrm{C}$-reaktif protein(CRP) takibi ile enflamasyon kontrol altında tutulur. Jonely ve ark., 35 yaşında nullipar bir kadın hastanın 14 yıldır mevcut sakroiliak eklem ve pelvik kemer disfonksiyonunu proloterapi ve manuel terapi seansları ile 1 yl sonunda visuel ağr1 skorunun 0 olduğunu göstermişlerdir(16). Proloterapi yöntemi en çok başarı omuz eklemi hastalıklanında(donuk omuz) başarılı olmaktadır. Eklem üzerine ağırlık binmediği için iyileşmesi daha çabuk olabilmektedir. Randomize çift kör yapılan bir çalışmada, ağrllı rotator kuf tendiniti ultrasonografi ile tesbit edilmiş fizik tedavi alan, 73 hastaya, proloterapi enjeksiyonlarınınuzun dönem iyileşme sağladığ1 gösterilmiştir(17). Proloterapi enjeksiyonu uygulanacak hastaların iğne kalınlıklarının fazla olması nedeniyle, kişilerin ağrı eşiklerinin yüksek ve enjektör uçlarını görmemeleri gerekmektedir. 
Alp, H., (2019). Birinci basamakta kronik ağrılı hastaların tedavi tercihlerini etkileyen faktörler ve kronik ağrıda güncel tedavi seçenekleri. Journal of Human Sciences, 16(3), 781-790. doi:10.14687/jhs.v16i3.5556

Enjeksiyon tedavilerinden bir diğeri de transforaminal enjeksiyonlardır. Hasta algoloji polikliniklerinde takip edilmektedir. Seçilmiş hastaların işlem öncesi aç karnına gelmesi sağlanmaktadır. , Ameliyathane şartlarında sedasyon verilerek skopi eşliğinde enjeksiyonları yapılmaktadır. Isşlem sonrasında da hastalar gözlem altında tutulmaktadır. Hastanın faset ve transforaminal eklem alanlarına lokal anestezik ve steroid karışımları enjekte edilmektedir. Hasta diabetik değilse çeşitli steroidler uygulanabilmektedir. Mc Cormick ve ark.yaptığı bir çalışmada $(n=78)$ elektromyografi ile doğrulanmış lumbosakral radikulopatili hastalarda çeşitli steroidlerin enjeksiyonu karşılaştırılmış; fakat ağnı azalımı açısından fark olmadığı belirtilmektedir. Hastanede kalış ve açlık süresinin uzun olması ve ameliyathane stresi yaşamaları hastaların bu tedavi seçimini negatif etkileyen faktörler arasındadır.

İlaç kullanımı ile geçmeyen kronik refrakter baş ağrilı hastalarda sfenopalatin ganglion enjeksiyonları yapılabilir. Ganglion enjeksiyonlarının uzun dönem çalışmalarda etkili olduğu literatür çalışmalarında gösterilmektedir(18). Kronik ağrı nedenlerinden küme tipi başağrıları stresle başlayabilir; insidansı \%0.1 civarındadır, tek göze lokalize olur, vazomotor belirtiler (göz yaşarması, rinore, myozis, ptozis) eşlik edebilir. Küme tipi baş ağr1sı epizodik ve sürekli olabilmekte ve tanısı genelde gecikmektedir. Randomize kontrollü çalışmalarda $6 \mathrm{mg}$ subkutan sumatriptan veya $12 \mathrm{l} / \mathrm{dk}$ oksijen tedavisi efektif bulunmuştur(19) .

Kronik ağrı tedavisinde kullanılan yöntemlerden biri de akupunkturdur.Vücutta çiğ denilen yaşam enerjisinin meridyenlerde durağanlı̆ga uğramadan akışı prensibine dayanmaktadır(20). Akupunktur vücutta endojen opioidlerin salınımına yol açar bu yüzden kronik ağriya eşlik eden depresyonun tedavisinde de kullanılmaktadır. Akupunktur uygulamasının bilinen hiçbir yan etkisi bulunmamaktadır. Kronik nöropatik ağnı yanısıra pek çok hastalı̆̆ın tedavisinde de kullanılabilmektedir. -Akupunktur hastalar arasında çok bilinmemekte, yaygın uygulama ortamı bulamamakta ve sosyal güvenlik kurumları tarafindan ödeme kapsamına henüz alınmamaktadır. Tüm kronik ağr1 giderici yöntemlerin hangi hastaya hangi yöntemin daha etkili olabileceği konusunda birinci basamak hekimlerine özellikle anamnez alma sırasında çok iş düşmektedir.

Anamnez alırken, hastayı hastanın ifadelerine karışmadan, etkili iletişim yöntemi kurarak dinlemek en doğru tutum olmaktadır. Ağrının başlangıcı, bitişi, süresi, şiddeti, zonklayıcı özelliği, ağrıyı başlatan durumlar, ağrının yayılımı, ağrının uykuyla olan ilişkisi, hastanın önceki tedavileri ve bu tedavilerin ağrı üzerine etkisi sorgulanmalıdır. Hastanın ağrılı dönemleri, geçirilmiş travmaları, hastalıkları, mesleği, yaşadığı ortam, alışkanlıkları, hayata bakışı, postür alışkanlıkları, aile öyküsü, ağrı öncesi ve sonrası ruhsal durumu, ağrı tedavisine karşı beklentisi sorgulanmalıdır. Hastanın ağrısını etkileyen faktörler; yaş, cinsiyet, eğitim durumu, yaşadığı ortam, maddi durum olabilmektedir. Falla ve arkadaşlarının yaptığı bir çalısmada $(\mathrm{n}=205)$, kronik ağrılı hastaların ağıı boyutunun hastanın cinsiyetinden ve finansal durumundan etkilendiği tespit edilmiştir(21).

Kronik ağrı, hastaların günlük yaşam aktivitelerini kısıtlayabilmektedir, ağrı nedeniyle hastalar psikolojik olarak kötü hissetmekte, bozulan psikoloji ile kişinin ağrı alg1sını etkileyerek bir kısır döngüye girmektedir. Hastanın kişilik yapısı ve emosyonel durumu, ağrıyı algılamasında ve ağriyı dile getirmesinde önemli bir faktördür. Psikolojik olarak iyi durumda olan hasta ağn1 eşiği yüksek ise ağr1 yakınması daha az olmakta, karamsar bir kişiliğe sahipse ağrı eşiği daha düşük olmaktadır. Depresyonlu kişiler ağnı düzeylerini abartılı şekilde gösterebilmektedir( 22 ). Kişinin hayatı boyunca yaşadığı kazalar, hastalıklar, sosyokültürel yapısı, hissettiği ağrıyı ifade etmesini etkileyebilir. Yapılan bir çalışmada düşük sosyoekonomik düzeyin somatizasyonla ilişkili olduğu ortaya konmuştur.(24).

\section{Sonuç ve Öneriler Çalışmanın Kullanılabilirliği}

Bu çalışma Aile Sağlığ1 Merkezinde tek bir aile hekimine başvuran kısıtlı sayıdaki hastalar üzerinde yapılmıştır. Örneklem sayısının daha fazla olduğu, çok merkezli geniş çapta çalışmalara ihtiyaç bulunmaktadır. Yapılacak geniş kapsamlı çalışmalar hastaların hangi tedavi yöntemini, neden tercih ettikleri konusunda daha açıklayıcı olacaktır. Kronik ağrı hastalarının tedavi seçeneklerini bilmesi ve yöntemler hakkında birinci basamak doktorlarından doğru bilgi alması, kendisine en uygun 
Alp, H., (2019). Birinci basamakta kronik ağrılı hastaların tedavi tercihlerini etkileyen faktörler ve kronik ağrıda güncel tedavi seçenekleri. Journal of Human Sciences, 16(3), 781-790. doi:10.14687/jhs.v16i3.5556

yöntemini seçmesi konusunda yol gösterici olacaktır. Bunun için de aile hekimlerinin kronik ağrı sağaltımında kullanılan tüm yöntemler hakkında güncel bilgilerle donanımlı olması gerekmektedir.

\section{KAYNAKLAR}

Barloese, MC., Jürgens, TP., May, A., ett all. Cluster headache attack remission with sphenopalatine ganglion stimulation: experiences in chronic cluster headache patients through 24 months. J Headache Pain. 2016 Dec;17(1):67.

Bertrand, H., Reeves, KD., Bennett, CJ., Bicknell, S., Cheng, AL.. Dextrose Prolotherapy Versus Control Injections in Painful Rotator Cuff Tendinopathy. Arch Phys Med Rehabil. 2016 Jan;97(1):17-25.

Çelik, C., Medical Akupunktur. Kuban Matbaacilık Yayıncılık. 2. Basım, 2001, Ankara.

Erdine, S., Hamzaoğlu, O., Özkan, Ö, Balta, E., Domaç, M., Türkiye'de erişkinlerin ăgrn prevalansı. Ağrr. 2001;13(2):22-30.

Falla D1,2, Peolsson A3, Peterson G3,4, ett all. Perceived pain extent is associated with disability, depression and self-efficacy in individuals with whiplash-associated disorders. Eur J Pain. 2016 Oct;20(9):1490-501.

Fillingim, RB., King, CD., Ribeiro-Dasilva, MC., Rahim-Williams, B., Riley, JL., 3rd. Sex, gender, and pain: a review of recent clinical and experimental findings. J Pain 2009;10(5):447-85.1 2001;13(2):22-30.

Joaquim, AF., Initial approach to patients with acute lower back pain. Rev Assoc Med Bras (1992). 2016 Apr;62(2):186-91 DOI:10.1590/1806-9282.62.02.188

Jonely, H., Brismée, JM., Desai, MJ., Reoli, R., Chronic sacroiliac joint and pelvic girdle dysfunction in a 35-year-old nulliparous woman successfully managed with multimodal and multidisciplinary approach. J Man Manip Ther. 2015 Feb;23(1):20-6.

Kesebir, S., Depresyon ve somatizasyon. Klinik Psikiyatri 2004;Ek 1:14-19.

Lautenbacher, S., Kunz, M., Strate, P., Nielsen, J., Arendt-Nielsen, L. Age effects on pain thresholds, temporal summation and spatial summation of heat and pressure pain. Pain 2005;115(3):410-8. DOI:10.1016/i.pain.2005.03.025

Levy, M., Pain control in patients with cancer. Oncology (Williston Park) 1999; 13: 9-14

Miller, C., Newton SE. Pain perception and expression: the influence of gender, personal self-efficacy, and lifespan socialization. Pain Manag Nurse 2006;7(4):148-52.

Perrin, GM., Altschule, MD., The physiologic response of schizophrenic and other psychotic patients to a standard emotional stress. N Engl J Med. 1957 Apr 11;256(15):682-8.

Price, DD., McGrath, PA., Rafii, A., Buckingham, B. The validation of visual analogue scales as ratio scale measures for chronic and experimental pain. Pain. 1983 Sep;17(1):45-56. DOI:10.1016/0304-3959(83)90126-4

Robinson, ME., Gagnon, CM., Riley, JL., 3rd, Price DD. Altering gender role expectations: effects on pain tolerance, pain threshold, and pain ratings. J Pain 2003;4(5):284-8. doi.org/10.1016/S1526-5900(03)00559-5

Portenoy, RK, Itri LM. Cancer-related fatigue: guidelines for evaluation and management. Oncologist 1999;4(1):1-10.

Saragiotto, BT., Machado, GC., Ferreira, ML., Pinheiro, MB., Abdel Shaheed, C., Maher, CG., Paracetamol for low back pain. Cochrane Database Syst Rev. 2016 Jun 7;(6):CD012230 doi: 10.1002/14651858.CD012230.

Sarpkaya, Ü., Karaağaç, H., Doğan, H., Grade, Gonartroz: Olgu Sunumu, Integr Tip Derg. 2016;4(1):32-37.

Özkan, Ö., Hamzaoglu, O., Erdine, S., Balta, E., Domac, M., Use of analgesics in adults with pain complaints: prevalence and associated factors, Turkey. Rev Saude Publica. 2009 Feb;43(1):140-6. DOI: $10.1590 / \mathrm{s} 0034-89102009000100018$

Yu, HY, Tang FI, Kuo BI, Yu S. Prevalence, interference, and risk. factors for chronic pain among Taiwanese community older people. Pain Manag Nurse 2006;7(1):2-11.

Tanrıverdi, G., Okanlı, A., Çetin, H., Özyazıcıŏlu, N., Sezgin, H., Özışı-Kararman, H. ve ark. Yaşh popülasyonunda ağr. Geriatri 2009;12(4):190-7.

Tfelt-Hansen, P.,. Maximum effect of triptans in migraine. A comment. Cephalalgia. 2008 Jul;28(7):767-8. DOI:10.1111/j.1468-2982.2007.01415.x

Theobald, DE., Cancer pain, fatigue, distress, and insomnia in cancer patients. Clin Cornerstone 2004;6 Suppl 1D:S15-21 doi.org/10.1016/S1098-3597(05)80003-1

The World Health Organization's Fight Against Cancer: Strategies That Prevent, Cure and Care. World Health Organization 2007. 
Alp, H., (2019). Birinci basamakta kronik ağrılı hastaların tedavi tercihlerini etkileyen faktörler ve kronik ağrıda güncel tedavi seçenekleri. Journal of Human Sciences, 16(3), 781-790. doi:10.14687/jhs.v16i3.5556

\section{Extended English Summary}

\section{Introduction}

When the reasons of referral to all polyclinics were examined, the most common reason for application after upper respiratory tract infections was pain. According to the literature, it is divided into 2 classes according to the duration of pain, acute and chronic. Chronic pain is shown to originate mostly from the lumbar region. Multidispliner approach is important for patients with chronic pain.

Every patient has musculoskeletal pain at a time of his life. Approximately $80 \%$ of the population is suffering from back-neck pain. Workers who do standing work have lower back pain over time and neck-shoulder pains are frequently encountered in those who do desk work.

Most of the employees do not know the correct posture characteristics, either do not care or cannot apply them according to the conditions. However, posture today is very important in our daily lives. Ergonomic work tables, computers postures and body frame provides positive effects. Frame forms the biomechanical axis of our body.

Posture disorders are involved in posturology. In the treatment, the patient is determined to be balanced on one leg and the instability side is detected and the problems related to the posterior $2 \mathrm{~mm}$ insit post cuff with instability are simply eliminated. In addition, proliferation is used in complementary medicine applications in correct posture.

Prolotherapy is especially used for treatment of ligament instability. The diagnosis of ligament instability can be made by orthopedics and physicians who are trained in physical therapy. Ligament instability is seen in many degenerative joint diseases as well as athletes. The ligament instability that may develop in patients operated for different reasons may cause pain in the patient. With complementary medicine applications such as prolotherapy, it offers new options for patients with advanced age degenerative bone disease who do not want to be operated in such cases. In appropriate patients, a correct history and physical examination can be performed to detect instabilities. Thus, larger surgical interventions may be delayed. In chronic pain conditions caused by degenerative joint diseases proliferation is very important.

One of the injection treatments is transforaminal injections. The patient is followed up in the algology outpatient clinics. The selected patients are allowed to arrive on an empty stomach before the procedure. In the operating room conditions, sedation is given and scoped injections are performed. Patients are kept under observation after the procedure. Local anesthetic and steroid mixtures are injected into the facet and transforaminal joint areas of the patient. Various steroids can be administered if the patient is not diabetic.

Acupuncture is one of the methods used in the treatment of chronic pain. It is based on the principle of flow of life energy called raw in the body without flowing in the meridians. Acupuncture leads to the release of endogenous opioids in the body, so it is also used to treat depression associated with chronic pain. Acupuncture has no known side effects.

Chronic pain can limit the daily activities of patients, because of pain, the patients feel psychologically bad, and the psychology and impaired psychology affect the person's perception of pain and thus enter into a vicious circle. The personality structure and emotional state of the patient is an important factor in perceiving pain and expressing pain.

\section{Materials and Method}

The sociodemographic characteristics of the participants were recorded on the forms prepared by the researchers.

\section{Findings}

The mean age of the patients was $58.62 \pm 10.72$.Pain was found to affect sleep. $(* p<0.05)$. 

tedavi seçenekleri. Journal of Human Sciences, 16(3), 781-790. doi:10.14687/jhs.v16i3.5556

\section{Results}

The patient sector, which is far from rational drug use, can cause great harm to the country's economy. With the extensive studies to be carried out, the treatment method of the patients and the reasons why they prefer. It will be helpful for the chronic pain patients to get the right information from their doctors about the treatment options. For this reason, family physicians should be equipped with up-to-date information about all methods used in chronic pain treatment.

This study was conducted on a limited number of patients who applied to a single family physician in the Family Health Center. A large number of multicentre studies are needed where the sample size is higher. Extensive studies to be done will be more explanatory on which treatment method and why patients prefer. The fact that chronic pain patients know the treatment options and get the correct information from the primary care physicians about the methods will guide him to choose the most suitable method. For this reason, family physicians should be equipped with up-todate information about all methods used in chronic pain treatment. 